\title{
A Power Efficient Mobile Solar Tracking System
}

\author{
Laura-Mihaela Leluţiu ${ }^{1}$, Carmen-Mihaela Lungoci ${ }^{1}$, Marius-Daniel Călin ${ }^{1}$, Marcian Cirstea ${ }^{2}$ \\ ${ }^{1}$ Electrical Engineering and Applied Physics Department, Transilvania University of Brasov, Romania \\ ${ }^{2}$ Computing and Technology Department, Anglia Ruskin University, UK \\ laura.lelutiu@unitbv.ro, lungoci@unitbv.ro, marius.calin@unitbv.ro, marcian.cirstea@anglia.ac.uk
}

\begin{abstract}
This paper is concerned with a portable automatic solar panel, mounted on a mobile trailer. The benefits of a mobile solar panel versus one mounted in a fixed position are highlighted. The paper focuses mostly on the efficiency of the solar panel, in relation to the sunlight angle with respect to the panel surface. The results of the analysis performed demonstrate the higher efficiency of the panel mounted on a sun tracking device with quantifiable differences reported in the paper.
\end{abstract}

Keywords: solar energy, photovoltaic panel, solar tracking system

\section{INTRODUCTION}

Nowadays, a large amount of energy is still produced from traditional fossil fuel sources such as oil and coal, which cause pollution and are damaging the environment in longer term. The modern trend in energy/electricity production is aligned to a move towards more sustainable renewable energy sources such as solar (photovoltaic) and wind energies [1-3].

The project tackled by the paper concentrates on the use of solar energy to generate electricity. In more detail, this is concerned with the design and hardware development of a portable automatic solar panel, mounted on a mobile trailer. Such PhotoVoltaic (PV) panel can be moved according to needs, the range of applications including: work sites, chalets, firework emergency sites, camping sites or other sites in need of electricity supply. The panels can be also used in tandem with batteries, in conjunction with diesel engines, or linked to the power grid. The most important challenges for the efficient operation of solar panels are linked to the weather conditions, the sunlight incident angle on the panel surface, and the high initial investment (development/setup costs) [4,5]. Solar panel applications are predicted to constitute a future boom in the industry, especially because other energy sources are polluting and they are being diminished constantly, leading to an inevitable exhaustion. In the meanwhile, their prices are seeing a significant increase [6, 7]. The overall efficiency of the electricity generated from a photovoltaic panel can be improved in relation to the mobile trailer carrying it and the position and angle of solar panel [8].

This paper approaches the efficiency of the solar panel with respect to the incident angle of the sunshine on the panel. The analysis performed quantifies the performance difference between a fixed position PV panel and one linked to a sun tracking device, thus demonstrating that they are noticeable. The motivation and research work led to the design of a highly efficient, portable and cheap automated solar panel power supply system, capable of providing the energy needed to sustain the automatic system and some small power consumers. The general requirements established at the project were: to develop the solar tracking system for maximum efficiency; to build the prototype for easy use and simple and safe transportation; to test the differences between a solar tracking system and fixed solar panel. A prototype was built, easy and convenient to use, with simple and safe transportation, in order to test and measure the differences between a mobile solar tracking system and a fixed solar panel. Its mobility had to be balanced against the intended efficiency, so it is important that the panel rotates after the sun light in order to get a satisfying power output.

\section{SYSTEM DESCRIPTION}

Several software packages have been used in this project. LabView and Solidworks were used for the simulation, while Arduino IDE and Fritzing (used for sketching the circuit diagram) were used for designing the schematic and programming the Arduino microcontroller board (Fig. 1); LabView software is useful for any measurement or control system development. This visual programming language is easy to use and can program an Arduino board or even motions in Solidworks [9, 10]. For the construction of the Solar Tracking Device, the following equipment has been used: the trailer build using the schematics made in Solidworks, the Eco Source Power Panel with its battery, an Arduino board, two Servos. The Eco Source Power Panel has: maximum power of $5 \mathrm{~W}$, sizes of $285 \times 185 \times 25 \mathrm{~mm}$, maximum voltage of $18 \mathrm{~V}$, maximum current of $0.277 \mathrm{~A}$, short circuit current of 21.6 A. The rechargeable Battery Mindtech MRD 1240 has: constant voltage charge, cycle use of $14.6 \mathrm{~V}-14.8 \mathrm{~V}$ $\left(25^{\circ} \mathrm{C}\right)$, standby use of $13.7 \mathrm{~V}-13.9 \mathrm{~V}\left(25^{\circ} \mathrm{C}\right)$, initial current less than 1-2 A, rated capacity of $4 \mathrm{Ah}$, rated voltage of $12 \mathrm{~V}$, mini cycle number of 1200 , service temperature of $-20^{\circ}$ $+60^{\circ} \mathrm{C}$. The Servo Motor is an Analog Servo - HD - 1501MG type, a metal-geared analog servo from Power HD that delivers extra-high torque normally associated with much more expensive or larger servos.

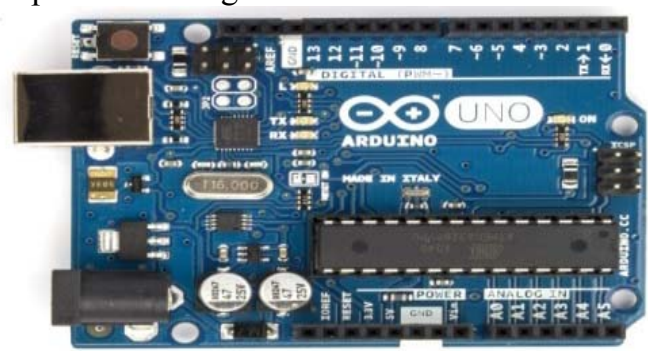

Fig. 1. Arduino Uno Rev3 microcontroller board view 


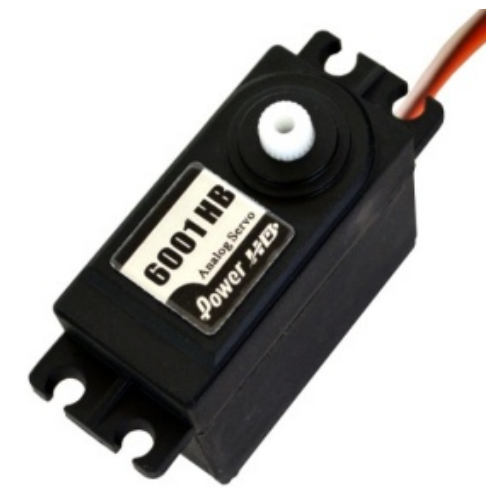

Fig. 2. Servo Power HD 6001HB

The HD-6001HB (Fig. 2) is an important general-purpose, standard-size servo motor which provides extra torque without sacrificing speed. Two ball bearings help reduce friction and improve performance.

\section{PRELIMINARY TESTS AND SIMULATIONS}

\section{A. Incidence Angle Test}

The incidence angle of the sunlight has a significant impact over the efficiency of a solar panel. Thus, the first pre-test carried out has analyzed different incidence angles of sunlight on a solar panel. For this pre-test, voltage and current calculations are needed in order to find out the power output. The independent variable is the incident angle of the sun on the solar panel, while the dependent variable is the power output. Firstly, the test is performed outdoors, at midday, when the sun is up on a clear day (Fig. 3).

The solar panel is positioned so that the incident angle is $\sim 90^{\circ}$ to sunlight, measuring the voltage generated by the panel, while adjusting the inclination angle until it reaches the position corresponding to the highest generated voltage. The height, $h$, and length, $l$, are measured with a gradual ruler. The angle $\sigma$ will be calculated using the following equation:

$$
\sigma=\operatorname{arctg}(h / l)
$$

where $\sigma$ is given in degrees and $h$ - the height of the panel and $l$ - the length of the panel are given in millimeters.

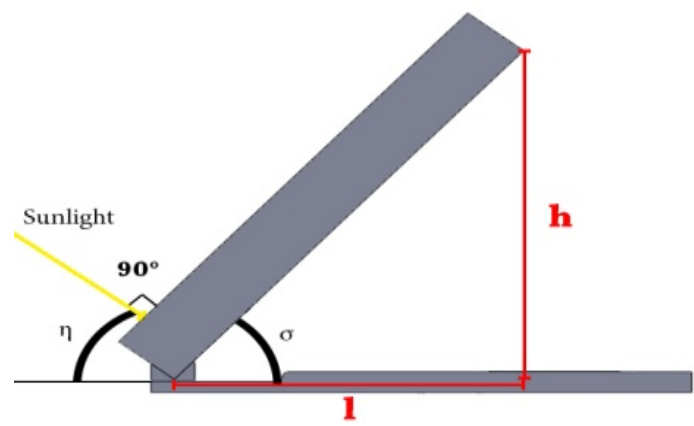

Fig. 3. Dimensions for panel 1
Next angle $\eta$ can be computed using equation 2 :

$$
\eta=180^{\circ}-90^{\circ}-\sigma
$$

For the other angles, the $90^{\circ}$ angle in equation 2 will be replaced with the new angles of $0^{\circ}, 15^{\circ}, 45^{\circ}, 60^{\circ}, 75^{\circ}$ respectively. The maximum power is computed with the help of a 3rd equation. As soon as a load is connected to the solar panel, in this case a Lamp or a DC Motor, $P_{\text {out }}$ will decrease.

$$
P_{o u t}=I_{s c} \cdot V_{o c}
$$

where $P_{\text {out }}$ is the maximum output power, $\mathrm{I}_{\mathrm{SC}}$ is the shortcircuit current, $V_{\mathrm{OC}}$ is the open-circuit voltage. The incident angle is then changed to: $75^{\circ}$ to sunlight, $60^{\circ}$ to sunlight, $45^{\circ}$ to sunlight, $30^{\circ}$ to sunlight, $15^{\circ}$ to sunlight, $0^{\circ}$ to sunlight, respectively. The measurements are repeated two more times for a precise result (Fig. 4, Fig. 5). A $50 \Omega$ resistance is used for this test in order to calculate the current using Ohm's law:

$$
I=U / R
$$

where $R=50 \Omega$ and $U$ is measured with the multimeter.

The chart results confirm the hypothesis that the solar panel has the highest power output when it is perpendicular to the sunlight and then declines as the angle decreases.

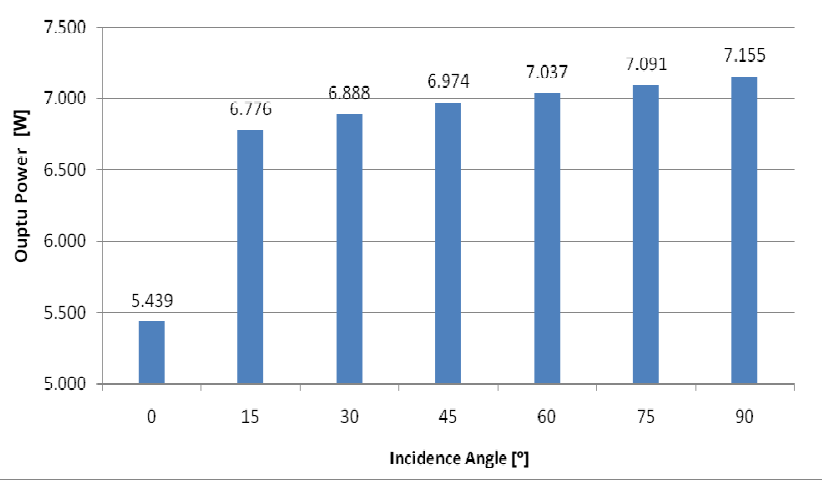

Fig. 4. Output power without load

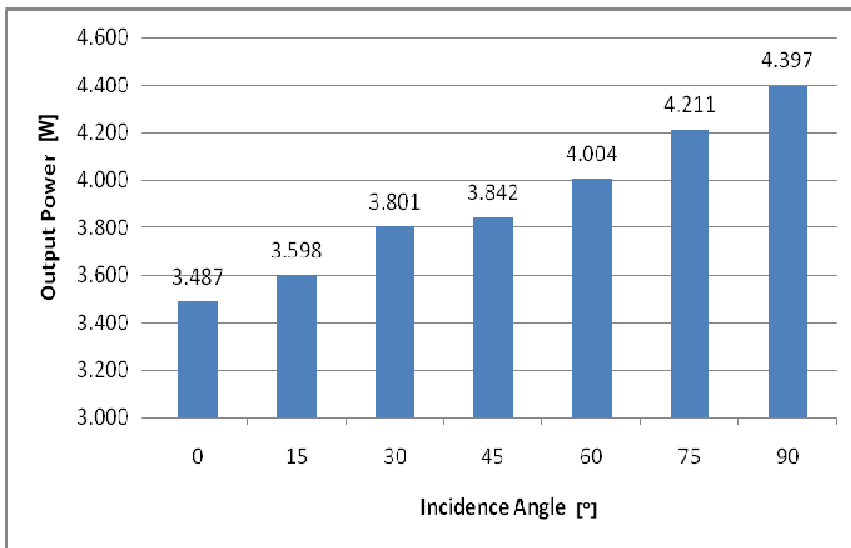

Fig. 5. Output power with a load 


\section{B. Non-rotation Pre-Test}

The second pre-test carried out consists of the measurement of the power output during a day when the solar panel is south oriented, positioned at an angle of $45^{\circ}$. Measurements are taken at 15 minutes interval from 8 o'clock to 20 o'clock. This test will show that the power output is small in the morning, reaches a peak at around $2 \mathrm{PM}$ and decreases afterwards. Hypothesis was right, the power increases, reaches a peak and decreases during a day if the solar panel is fixed on a position facing south at a $45^{\circ}$ angle (Fig. 6). It can be noticed that the power output varies significantly during a day; in the morning and evening, because the panel is fixed, the sunlight does not fall perpendicular to the solar panel, therefore, this is a case of reduced energy output.

\section{Pre-Tests Conclusions}

The results of the two pre-tests show that the incident angle is very important and that the panel should always be oriented towards the sun. A small difference in the incidence angle is already visible in the power output. Later, another test will be performed when the solar panel will track the sun, aiming to quantify the differences between a solar tracking device and a fixed mounted solar panel.

\section{Simulation}

A 3D simulation of the solar panel was carried out. For this simulation, Solidworks software was used for the 3D model and LabView software for connecting the simulation with Arduino. The 3D simulation is made in order to see the movement of the panel and to determine how to build the trailer for the panel. A simple model was build (Fig. 7.). Two servo motors and a potentiometer were connected to Arduino.

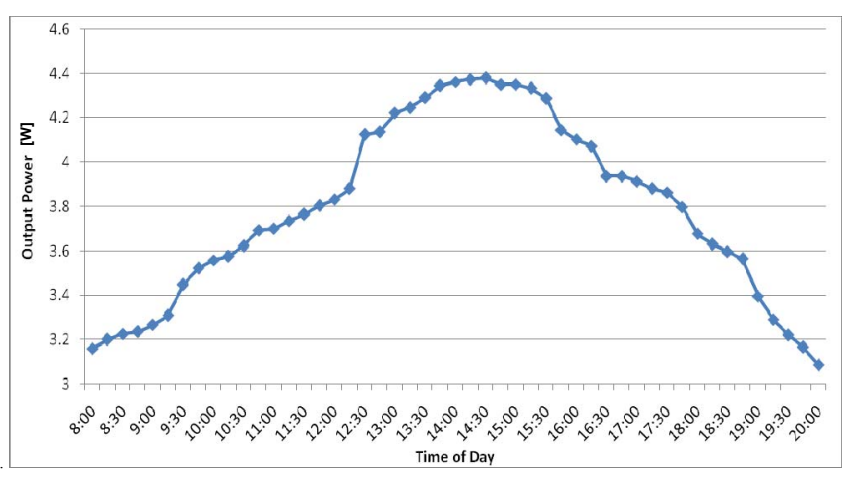

Fig. 6. Power output during a day with a fixed solar panel

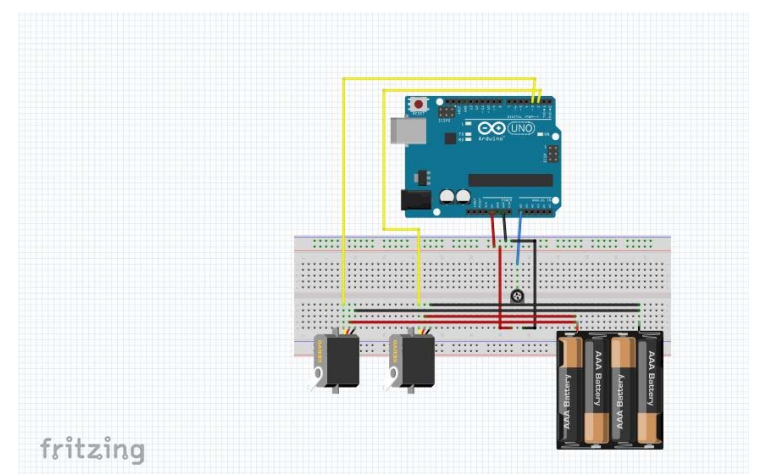

Fig.7. Fritzing diagram for the simulation assembly
The potentiometer was used for controlling one of the Servo Motors, while the second Servo Motor was controlled from LabView. While moving the potentiometer, LabView receives the input data from it and sends it as an output to the $3 \mathrm{D}$ simulation as well as to the Servo Motor. The potentiometer sends to the Arduino's ADC values from $0 \mathrm{~V}$ to $5 \mathrm{~V}$. With a simple transformation in LabView, the values from 0 to 5 are transformed to values from 0 to 180 .

The Solidworks assembly and the axes needed for the motion study were added together, in order to carry out the simulation. Each axis was connected to a "RotaryMotor" attached in Solidworks Simulation. Fig. 8 illustrates pictures of the front-end and of the back-end VI interfaces.

The Knob is placed for changing the position of the Servo Motor in the LabView Simulation, while the other Gauge is there to point the value at which the other Servo Motor is located. The Value from the Gauge changes when there is a change in the Potentiometer. The same movement can be seen into the Simulation as well. With the help of Solidworks, the file with all the parameters needed in order to build the physical/hardware version of it was generated. The motion in Solidworks is achieved through LabView; changing the position of the potentiometer or the position of the knob moves the position of the Servo Motors in the simulation and also of those connected to the Arduino microcontroller board.

The co-simulation of Arduino, LabView and Solidworks can make a $3 \mathrm{D}$ version of a larger system and simulate it in LabView, controlled directly from LabView or from Arduino. After the 3D model was achieved (Fig. 9, Fig. 10), a project was created in LabView in order to add the simulation assembly from Solidworks.
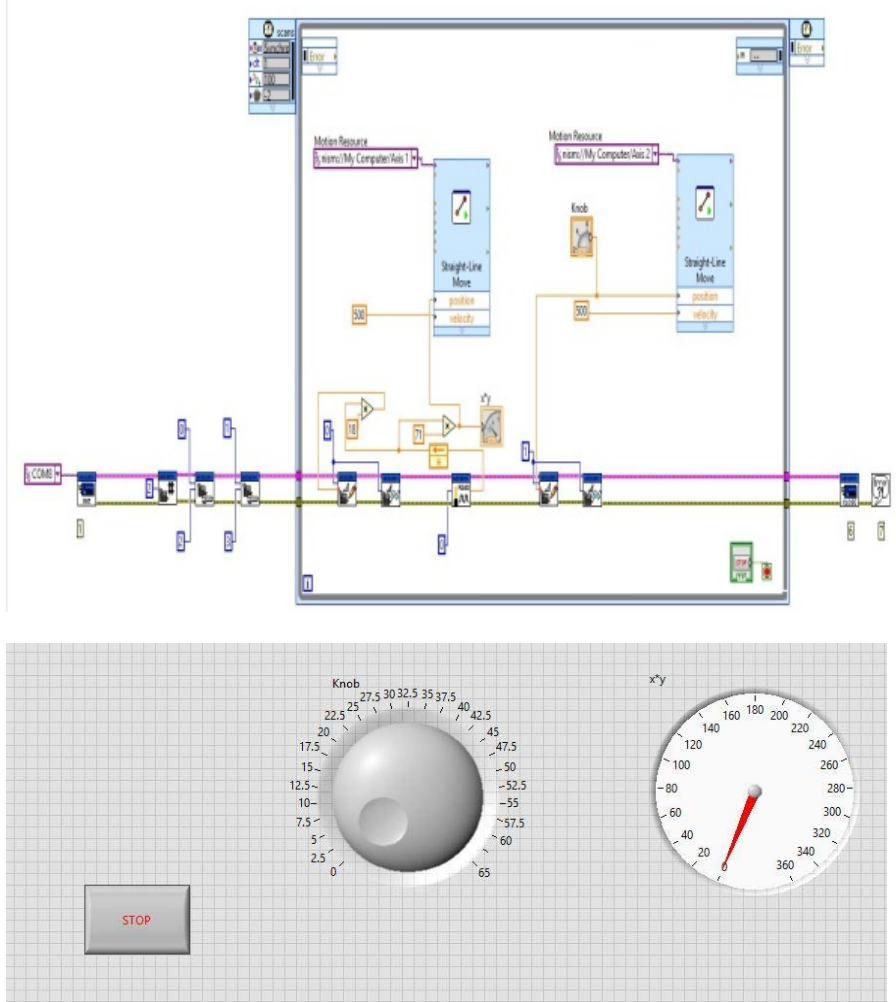

Fig. 8. LabView back-end and LabView front-end 


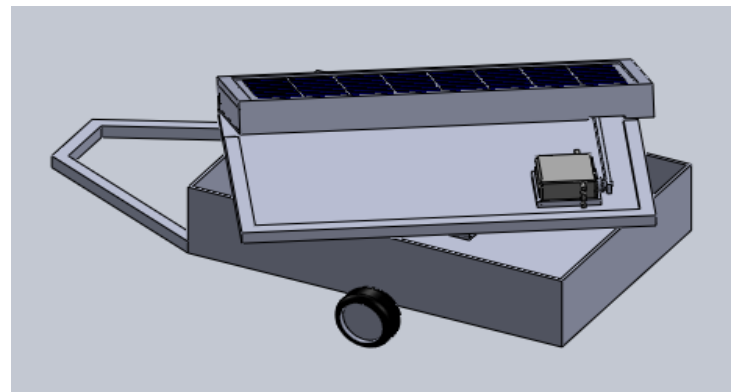

Fig. 9. Solidworks 3D model A

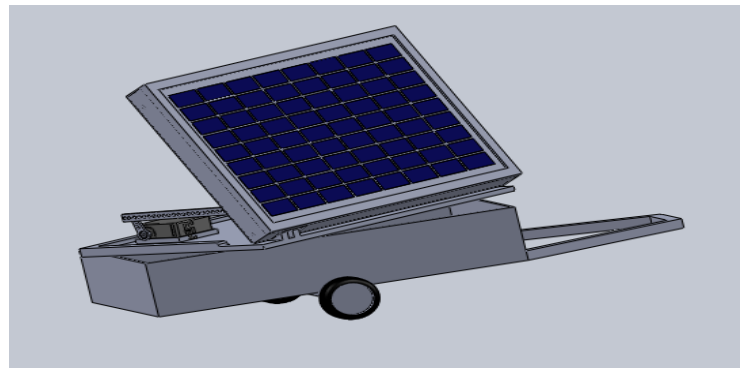

Fig. 10. Solidworks 3D model B

The simulation provided helpful information about the movement of all the elements in the system and about the difference between the angle of the servo and the actual angle in which the solar panel will be positioned. Because the servo is not exactly at the joint, the angle of the panel is smaller than the angle of the servo. A $90^{\circ}$ angle on the servo will be approximately equivalent to a $75^{\circ}$ angle on the solar panel.

\section{HARDWARE PROTOTYPE DEVElopMENT}

After the simulation, the hardware prototype development was initiated. Firstly, the upper part was built - the solar panel was attached with two hitches on one side of a board having the size of the panel. On the other side, the panel was free, so that the tilt of the panel will be possible. The Analog Servo HD - 1501MG has been used for the tilt movement because it is more powerful than the other Servo type used in this project and could tilt the solar panel, different from the Analog Servo Power HD Standard 6001HB that has been used only for the rotation of the board with the solar panel. Another difference between the two Servos is that the first one has a slightly different mechanism which holds it in the last position, even when the current is turned off. This means that after the panel is inclined to an angle, the panel will not return to its initial position, but will stay in the last position reached when the power was turned off. After completing the tilt movement, the upper part of the model was almost finalized. Four holes were made where the Photocells were placed for the panel automation. The second part of building the model was the inside part of the trailer. The USB was used for the Arduino board, so together with the input jack, it was mounted inside. Finally, the two parts where assembled together. The upper part should rotate above the trailer, so the Analog Servo Power HD Standard 6001HB was used for that operation. This Servo Motor rotates $180^{\circ}$ with a $1^{\circ}$ step. To achieve automation, a full rotation of $360^{\circ}$ was necessary. Two gearwheels were used, one with the double numbers of teeth mounted on the servo and the other mounted on the upper part of the assembly. With two gears, the ratio becomes 1 to 2 , meaning that a full rotation of the big wheel will rotate the smaller one twice. The $180^{\circ}$ Servo Motor becomes in this way a $360^{\circ}$ servo with a $2^{\circ}$ step. Such $2^{\circ}$ step is precise enough to achieve good automation. The Servo Motor was mounted inside the trailer on some wood pieces in order to lift it right under the solar panel; its gearwheel was covered in a $3 / 4$ housing to protect it from the cables that move around when turning the panel. The four photocells will be mounted on the four sides of the solar panel, in order to track the sun. As seen in Fig. 11, they are mounted in order to have an easy way of tracking the sun. The sensors are accurate enough to detect which sensor is the closest to the sun position and which one is shadowed by the panel. The photocells were connected to Arduino board with a $10 \mathrm{k} \Omega$ resistance for easier reading of the values. The solar panel will have the following routine. It is assumed that the trailer is in position with the solar panel situated down on it. The tolerance is $\sim 5 \%$ for this test. Once the photocells are powered, the information starts being received (Fig. 12). After the sensors gathered the data, the microcontroller will know exactly which has the highest value, meaning the sun is somewhere in the area of that sensor. If this is the Bottom Sensor, it checks the Left and Right Sensor and rotates it accordingly, so that both sensors should be in the tolerance area. Following on, the panel is raised, first to $40^{\circ}$, than more or less so that the Bottom Sensor and the Top Sensor have the same value between the tolerance areas. These measurements will be then repeated at every 15 minutes. The time interval of 15 minutes is used.

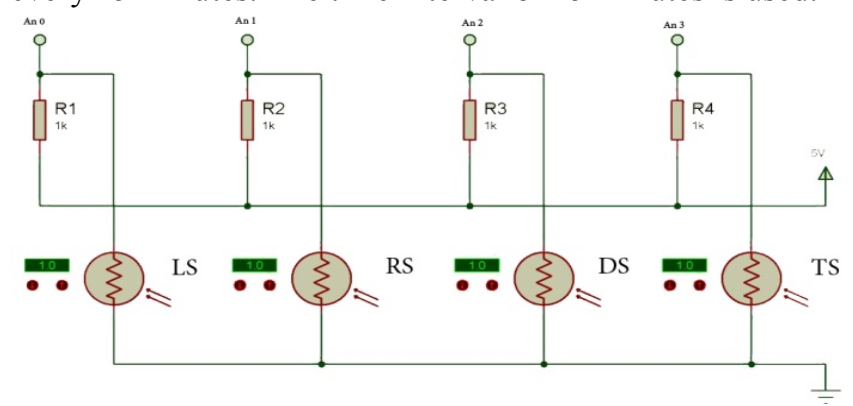

Fig. 11. Sensors schematic

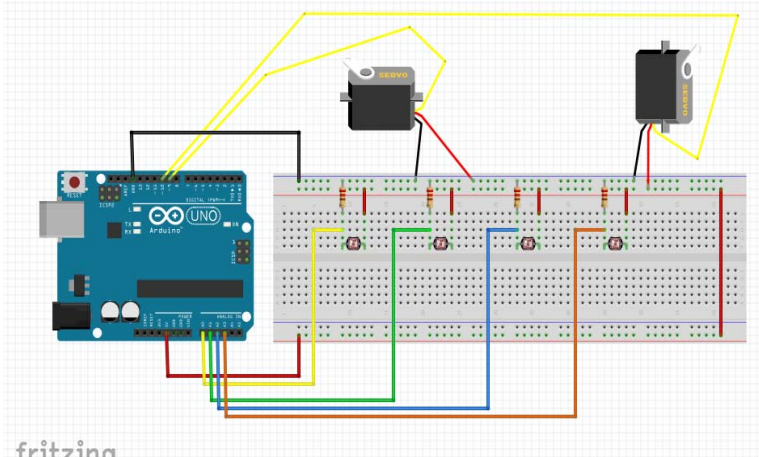

Fig. 12. Photocells and Servo connection to Arduino 
V.

The same tests as before are repeated, this time though, the panel is not in a fixed position, but tracks the sun. The average power output during the test day with the solar tracker is $4.390 \mathrm{~W}$, as it can be seen in Fig. 13. The differences between the power outputs during a day with a solar tracker system are not so big; the solar panel reaches the peak output value early and keeps it constant for a longer period of time before decreasing again.

It is seen that the power output is constant during a day with the solar tracker system, while with a fixed panel the power output is low in the morning, increases until midday and drops afterward (Fig. 14). The tests were carried out in two different days, with the test for the fixed panel being done on a sunnier day. Although the difference is significant, (approx.15\%), the real gain achieved through the use of the mobile system is expected to be higher in reality, because of the different weather conditions during the two test days.

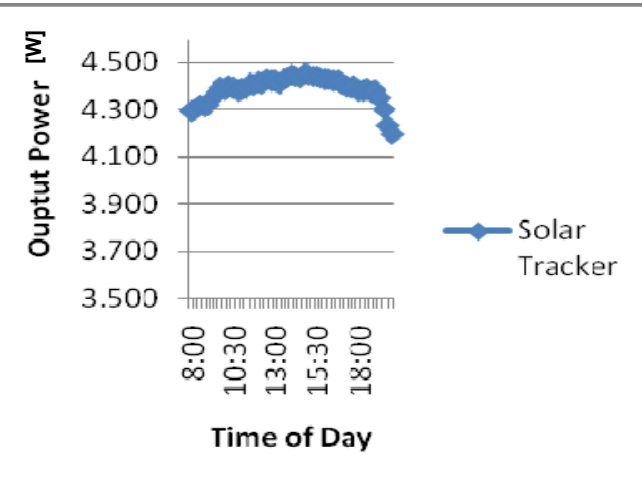

Fig. 13. Power output during a day with a solar tracker

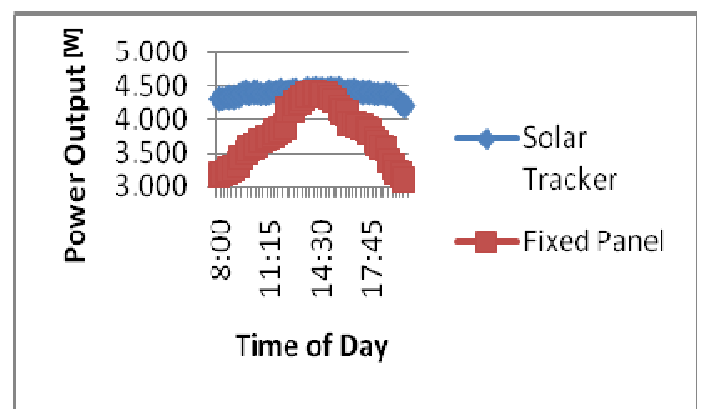

Fig. 14. Power output between a fixed panel and a solar tracker

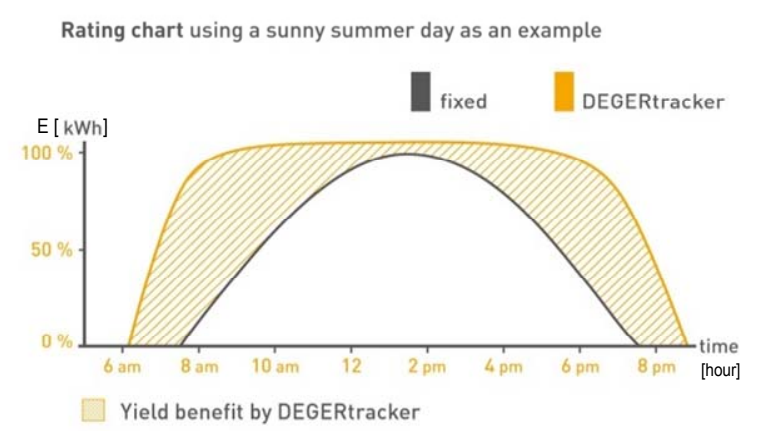

Fig. 15. Benefits of using a solar tracker [5]
As it can be seen in Fig. 14, the highest differences in the power generated as part of the two tests are in the morning and afternoon, due to the fact that the angle at which the sunlight aligns with the fixed solar panel is not optimized in the morning, thus losing a significant amount of energy. In the morning, using a solar tracker, the solar panel is turned towards the sun, thus increasing the power output in the early hours of the day. The peak power value is reached faster and it is then maintained for a couple of hours, while in the afternoon, the output power decreases slower, increasing the average output power during a day. This difference increases if the fixed panel is set at an average incidence angle between summer and winter. Thus, neither in winter nor in summer, the fixed solar panel reaches the best output, while the solar tracking device adjusts its angle during seasons. In the summer, the tilt angle is smaller, while in winter it increases up to more than $35-40 \%$ (Fig. 15).

Some further improvements can eventually be made to this prototype system. The servo motor mounted for rotation can be replaced with a bigger one that supports a $360^{\circ}$ rotation, or another rotation system can be developed, so that the cables to go from the panel down to the trailer through the middle without having the possibility to rotate until breaking. The replacement of the actual solution with a motorized crank, controlled by the microcontroller, is another potential improvement. In terms of improvements to the actual tracking system, while the sensors used currently are small (an advantage), they may not be sufficiently precise to be used in a larger system. An improved tracking solution could be achieved through the use of a GPS system, programmed to compute its position, altitude, rotation with the time of year, etc., thus following the sun much more precisely.

Even though PV modules' efficiency factor has been improved considerably over the last few years, the physical flattening has essentially been reached. A genuine jump in systems' efficiency can only be achieved through intelligent tracking, thus, generating more energy. This is best illustrated through an example. The Spanish solar park operator Picanda Solar has compared the yields of its photovoltaic systems for years. The results showed that the fixed module installations yielded about $1,500 \mathrm{kWh} / \mathrm{kWp}$ in comparison with 2,200 $\mathrm{kWh} / \mathrm{kWp}$ with Deger 5000NT tracking device. This is a yield improvement of $46 \%$ [3].

\section{EVALUATION IN ECONOMIC CONTEXT}

The payback time investment for solar panel systems such as the one developed as prototype can be only estimated at actual oil prices and solar energy prices and is hard to predict the depreciation time. Predictions are that the payback time will decrease - a current investment pays off only after more than 10 years. The expectations of faster payback time in the future are linked to the continuous research in this field. The battery prices are expected to drop in the future and their storage capacity and efficiency may increase dramatically. If this happens, not only solar power energy panels will be 
cheaper and better designed, but also electric cars and other devices that require high capacity batteries will see an increased demand. Another reason of this estimated decreasing payback time is the rapid reduction in fossil fuel resource reserves, so the energy prices linked to such conventional energy sources are likely to increase as well in the future. This kind of installation currently has applications for specific situations and locations without an energy source, as its costs are still high comparing with traditional sources.

An example of the costs related to various parts of a real system is given. The following parts should be taken into account. 6 polycrystalline $200 \mathrm{Wp}$ solar panels, Shutten model made in Germany - all 6 panels produce in a day $7.2 \mathrm{~kW}$. Each solar panel costs 150Euro. For the 6 panels, 4 rechargeable batteries of $250 \mathrm{Ah}$ are needed in order to store $12 \mathrm{~kW}$ power. From $12 \mathrm{~kW}$, nearly $8-9 \mathrm{~kW}$ can be used. Compared to a car battery, which can use only $15 \%$ of its capacity, this gel type based rechargeable batteries can use more of their capacity. The batteries used are 4 Caranda type of 250Ah costing 2000 Euro. One inverter is needed; a $2 \mathrm{~kW}$ Outback USA model at a cost of 900 Euro. Thus, two 50W LED projectors can be powered for 80 h, i.e. 8 days, if used 10 hours nightly. A load regulator is also needed because the solar panel gives fluctuating current that needs to be transformed into constant 12V [11]. A 45A regulator Steca Swiss model TAROM 4545 is around 100 Euro. The trailer costs an additional 1000 Euro (Fig. 16). Thus, such system would incur quite a high initial development cost, as it is the case with many renewables. As it is known, the housings for outdoors automation equipment is must provide a minimum degree of protection IP65. Due to reduced fabrication cost difference between production of enclosures with IP66 or IP67 degree of protection, it was chose an IP67 protection degree casing.

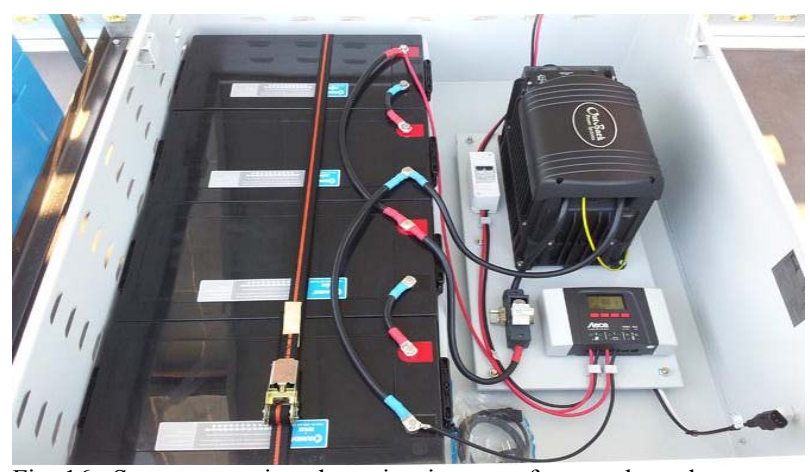

Fig. 16. System overview: batteries, inverter, fuses and regulator

\section{CONCLUSIONS}

Current work has confirmed that a fixed solar panel is characterized by big variations of the power output delivered during a day and also during different seasons of a year. It was also confirmed that a solar tracking device increases the average output power delivered during a day. A solar tracking device is normally cost-effective only for larger installations, due to the added cost of the tracking systems. For this reason, a cheaper solar tracking device was proposed as prototype. This kind of system can be mounted on a mobile device such as a trailer or a fire truck, for specific applications. Because of the higher initial cost of trailer, batteries, inverters etc., at first sight it appears that a solar panel built on a mobile device is unlikely to be cost-effective for mass usage. However, it has the benefit to provide power in situations and in places where there is no constant need of electricity or where other sources are not immediately available, with the added advantage of being a 'clean' and renewable source of electricity. Other potential applications are the systems mounted on fire engines or mobile solar generators for highways maintenance (generating electricity to drill a hole, paint, wash etc.). The work pointed out the benefits of higher output power generated by a mobile solar tracking device used for solar panels, compared to fixed PV systems. It is projected that solar trackers will soon be seen on many new solar installations [6].

\section{REFERENCES}

[1] P. Nema, R. K. Nema, and S. Rangnekar "A current and future state of art development of hybrid energy system using wind and PV-solar: A review", Renewable and Sustainable Energy Reviews, vol 13, pp. 2096-2103, 2009.

[2] R. Pitz-Paal, "Solar Energy - Concentrating Solar Power," in Future Energy: Improved, Sustainable and Clean Options for our Planet, London, London Elsevier, p. 738, 2013.

[3] D. Yogi Goswami, F. Kreith, and J. Kreider, "Principles of Solar Engineering," Second Edition, Taylor and Francis, p. 694, 2000.

[4] H. I. Cristian, and M. Raducu, "Energy efficiency analysis of various topologies, control techniques and technologies used for photovoltaic panels Part I: On the PV modeling and problem of extracting the maximum power", Proceedings of the 6th Int. Conf. on Electronics, Computers and Artificial Intelligence, pp. 23-28, 2014.

[5] J. Peng, and L. Lu, "Review on life cycle assessment of energy payback and greenhouse gas emission of solar photovoltaic systems," Renewable and Sustainable Energy Reviews, vol. 19, pp. 255-274, 2013.

[6] C. Marken, "Solar collectors: Behind the glass," HomePower, vol. 133, pp. 70-76, 2009.

[7] E. Helerea, and A. Munteanu, C. Marinescu, L.M. Rab, "Energy and environmental engineering," ISBN 978-973-508-065-6, Transilvania University of Brasov, 2007.

[8] M.S. Nicolae, A. Tudoraşcu, P. M. Nicolae, R. Saray, B. Kall, and G. Rambolamanana, "Optimization design of photovoltaic systems and improving their energy efficiency through a novel technology installation of the support", Int. Conf. on Applied and Theoretical Electricity, pp. 1-6, 2014.

[9] K. Bhise, N. Pragallapati, S. Thale, and V. Agarwal, "LabVIEW based emulation of photovoltaic array to study maximum power point tracking algorithms," 38th IEEE Photovoltaic Specialists Conf., pp. 002961-002966, 2012.

[10] Lelutiu L., "Measuring,data acquisition and processing systems," Transilvania University of Brasov, ISBN 978-606-19-0304-7, 2013.

[11] F. H. Aghdam, and M. Abapour, "Reliability and cost analysis of multistage boost converters connected to PV panels," IEEE Journal of Photovoltaics, vol. 6, no. 4, pp. 981-989, 2016. 